\title{
Human Leucocyte Antigen Class I Diversity among Human Immunodeficiency Virus Exposed Negative and Positive Children in Cameroon
} Céline Nguefeu Nkenfou ${ }^{1,2^{\star}}$, Elisa Nemes ${ }^{1,3}$, Linda Mekue ${ }^{1,4}$, Alba Grifoni $^{5,6}$, Beatrice Dambaya $^{1,2}$, Elvis Ndukong
Cappelli, $^{1,4}$, Carla Montesano ${ }^{5}$, Vittorio Colizzi ${ }^{5}$ and Massimo Amicosante ${ }^{6,7}$

'Systems Biology Laboratory, "Chantal Biya" International Reference Centre for Research on HIVIAIDS Prevention and Management (CBIRC), Yaounde, Cameroon 2University of Yaounde I, Yaounde, Cameroon

${ }^{3}$ South African tuberculosis vaccine initiative (SATVI), university of Cape Town, South Africa

${ }^{4}$ Faculty of Sciences, University of Dschang, Dschang, Cameroon

${ }^{5}$ Department of Biology, University of Rome "Tor Vergata", Rome, Italy

${ }^{6}$ ProxAgen OOD, Sofia, Bulgaria

${ }^{7}$ Department of Biomedicine and Prevention, University of Rome "Tor Vergata", Rome, Italy

\begin{abstract}
The link between HLA types and HIV disease progression has been well established with alleles and residues associated to progression or non-progression to AIDS. Vertical transmission rate of HIV in Cameroon is still very high $(10 \%)$. The aim of this study was to describe the diversity of HLA class I in infants born to HIV infected mothers and to determine the influence of HLA genotype in mother to child HIV transmission in Cameroon. Thirty four HIV infected infants and 28 HIV exposed but non infected infants born to HIV-positive mothers were enrolled in this study. HLA-A, HLA-B, group allele frequencies were determined by low-resolution polymerase chain reaction using sequencespecific primers. Nineteen HLA-A, 20 HLA-B allelic groups were identified in the study population. Among all the allelic variants identified, only HLA-B*44 allelic frequency resulted significantly increased in exposed non infected children (12.5\% in exposed non infected versus $2.9 \%$ in exposed HIV-infected children, $p=0.04$ ). HLA-B 44 may be associated with the resistance to HIV infection upon mother to child exposure.
\end{abstract}

Keywords: Pediatric HIV; Human Leucocyte Antigen; HLAB ${ }^{\star} 44$; Protection

Abbreviations: HIVe: HIV-Exposed Uninfected; HIVi: HIV Infected; HIVn: HIV-Unexposed; HLA: Human Leucocyte Antigen; PMTCT: Programs for the Prevention of Mother to Child transmission

\section{Introduction}

HLA, the most genetically diverse loci in the human genome [1], play a crucial role in host-pathogen interaction by mediating innate and adaptive cellular immune responses [2]. For a vast number of infectious diseases various HLA alleles have been associated with disease outcome. However, limited information is available about HLA in Central Africa where diseases such as HIV/AIDS, Hepatitis, malaria, tuberculosis and dengue fever are largely diffused.

The genetic make-up of a person's HLA affects the rate of HIV disease progression [3]. It has been shown that HLA class I alleles $B^{\star} 27$ and $B^{\star} 57$ are associated with better disease prognosis, while others (such as $B^{\star} 35$ ) are associated with worse outcome. The protection is not entirely explained by a confounding effect of a few highly protective HLA-B types such as $B^{\star} 57, B^{\star} 58, B^{\star} 27, B^{\star} 51$, and $B^{\star} 81[4,5]$.

Perinatal HIV-1 infection is influenced by a combination of virologic [6], immunologic and host factors. In recent years, a number of studies have suggested that host genetic factors are important determinants of both the susceptibility to perinatal HIV-1 infection and the subsequent pathogenesis of acquired immunodeficiency syndrome (AIDS). Control of HIV-1 infection involves the processing of specific viral peptides and their presentation to cells of the immune system by highly polymorphic human leukocyte antigen (HLA) alleles. The contribution of multiple HLA class I and II alleles in modulating pediatric HIV/AIDS outcomes has now been confirmed by several independent groups. HLA $A^{\star} 02$ has been shown to have a protective effect for the vertical transmission [7]. The haplotypes HLA-A3-B7-DR2 [8,9] and HLA-DR13 [9] have a protective effect against the MTCT. The recently described HLA-G 14 bp depletion [10] have a protective effect for MTCT. On the contrary, HLA-A1-B8-DR3 [8,9] and HLA-DQB ${ }^{\star} 0604$ [11] are associated with higher mother to child transmission risk. It has been shown that HIV-1 co-receptor usage influences on mother to child transmission as well as pediatric infection, although with contradictory data like the case of CCR2-64I [12].

One study found that mothers with HLA-B variants $\left({ }^{\star} 1302,{ }^{\star} 3501\right.$, $\left.{ }^{*} 3503,{ }^{*} 4402,{ }^{*} 5001\right)$ transmitted HIV to their infant even in the context of low viral loads, whereas mothers with other variants $\left({ }^{\star} 4901,{ }^{\star} 5301\right)$ did not transmit the virus despite high viral loads [13]. Furthermore, mother-infant pairs discordant with regards to the $H L A-G$ variants $3743 C / T, 634 C / G$, or 714 ins $G / G$ have been shown to experience a lower risk of HIV MTCT compared to concordant mother-child pairs [14].

HIV-exposed uninfected (HIVe) children are a rapidly growing

*Corresponding author: Céline Nguefeu Nkenfou, Systems Biology Laboratory "Chantal Biya" International Reference Centre for Research on HIVIAIDS Prevention and Management (CBIRC), Yaounde, Cameroon, Tel: +237 755735 19; Fax: +237 22 315456; E-mail: nkenfou@yahoo.com

Received December 18, 2014; Accepted March 05, 2015; Published March 15, 2015

Citation: Nkenfou CN, Nemes E, Mekue L, Grifoni A, Dambaya B, et al. (2015) Human Leucocyte Antigen Class I Diversity among Human Immunodeficiency Virus Exposed Negative and Positive Children in Cameroon. J AIDS Clin Res 6: 439. doi:10.4172/2155-6113.1000439

Copyright: (c) 2015 Nkenfou CN, et al. This is an open-access article distributed under the terms of the Creative Commons Attribution License, which permits unrestricted use, distribution, and reproduction in any medium, provided the original author and source are credited. 
population. Programs for the prevention of mother to child transmission (PMTCT) have reduced the transmission rate of perinatal HIV infection to approximately $2 \%$ to $5 \%$ [15-17]. Such programs have therefore effectively reduced the number of HIV infected (HIVi) children but identified an increasing population of HIVe children [18].

HIVe children have been overlooked as a group of children who may be at an increased risk of illness compared to HIV-unexposed (HIVn) children. Recently, increased morbidity and mortality in HIVe children compared to HIVn children has been reported [18-24]. Many factors may account for this including innate deficiencies in immunity, [2527] feeding practices [28], poor protection from maternal antibodies or environmental exposures [20].

Several research groups [29-32] have reported significant phenotypical differences between HIVe and HIVn infants; the most consistent finding is that of a more antigen-experienced cellular phenotype, which could be driven by exposure to HIV or its proteins.

In the present study, we describe the diversity of HLA class I in infants born to HIV infected mothers and to determine the influence of HLA genotype in perinatal HIV transmission in Cameroon.

\section{Material and Methods}

\section{Subjects and sample collection}

Infants born to HIV-1 infected mothers aged between 0-12 years were enrolled in this study. A total of 62 children were enrolled and distributed as follow: 28 exposed non infected, 34 exposed and infected. Study population characteristics are summarized in Table 1.

The study protocol was approved by the ethical committee of CIRCB. From these infants, $5 \mathrm{ml}$ of blood were collected in EDTA tubes. When possible, $\mathrm{PBMC}$ was prepared or the buffy coat was collected and stored at $-80^{\circ} \mathrm{C}$ until further analysis. DNA was extracted either from PBMC or from buffy coat using the Qiagen QiaAmp DNA mini-kit according to the manufacturer's instructions (Qiagen S.A 3 Avenue duCanada, LP 809, 91974 Courtaboeuf Cedex, France).

\section{CD4 count and Viral load}

CD4+ T cells were quantified on a FACSCalibur flow cytometer (Becton Dickinson Immuno-cytometry System (BDIS), San Jose, CA, USA).

The HIV-1 viral load was determined from plasma by Abbott Real-time HIV-1 assay (Abbott Molecular Diagnostics, Wiesbaden, Germany)

\section{HLA typing}

HLA genotyping was done using the Micro SSP kit from One

\begin{tabular}{|l|c|c|}
\hline Parameter & $\begin{array}{c}\text { Exposed infected } \\
\mathbf{( 3 4 )}\end{array}$ & $\begin{array}{c}\text { Exposed non } \\
\text { infected (28) }\end{array}$ \\
\hline Sex distribution (\% female) & 59 & 46 \\
\hline $\begin{array}{l}\text { Age distribution } \\
\text { Median age (years) }\end{array}$ & $1.2 \pm 0.95$ & $6.8 \pm 3.2$ \\
\hline Viral load range (copies $/ \mathrm{ml})$ & $143-3273260$ & Not applicable \\
\hline CD4+ range (absolute (\%)) cells $/ \mathrm{mm}^{3}$ & $283(16)-2366(18)$ & Not applicable \\
\hline & $\begin{array}{c}\text { CDC stage } 1: 18 \\
\text { CDC stage 2:12 } \\
\text { CDC stage 3:3 } \\
\text { CDC stage 4:1 }\end{array}$ & Not applicable \\
\hline
\end{tabular}

Table 1: Study population characteristics.
Lambda according to the manufacturer's instructions (One Lambda 21001 Kittridge St Canoga Park, CA 91303-2801, USA).

\section{Statistical analysis}

Data is presented as percentage. Fisher's exact test and Chi-square test have been used for comparisons between groups as appropriate. Bonferroni's correction has been used for multiple comparison correction. The Hardy-Weinberg equilibrium (HWE) was determined using popgene software. (http://www.ualberta.ca/ fyeh/popgene. html).

\section{Results}

The number of alleles, their frequency and the phenotypic frequencies were identified in the study population for HLA class I A and $B$ loci, respectively in the whole study population. Multiple allelic group of the HLA-A $(\mathrm{N}=19)$ and HLA-B $(\mathrm{N}=21)$ were identified, of which $A^{\star} 02$ allele frequency $(\mathrm{AF}=25 \%)$ and $\mathrm{B}^{\star} 58(\mathrm{AF}=14 \%)$ were the most frequent individual group alleles identified. All allelic groups resulted in HWE equilibrium.

Difference in the HLA-A and -B allelic frequencies between HIVexposed infected and not-infected children is presented in Table 2 and 3 respectively. Only HLA-B ${ }^{\star} 44$ resulted with an increase allelic frequency in exposed non infected $(12.5 \%$ in HIVe versus $2.9 \%$ in $\mathrm{HIVi}$, $\mathrm{p}=0.04$ ). As well the phenotypic frequencies of HLA A and HLA B (presented respectively in Tables 4 and 5) showed a statistical difference in HLA B ${ }^{\star} 44$ to be associated with the protection of Mother to Child Transmission with $\mathrm{p}$ value $=0.03$.

However, no differences where found after Bonferroni's correction likely for the small size study groups.

Finally, the HLA-A and HLA-B allelic groups were grouped accordingly to carry Bw4 or its counterpart Bw6 epitope. No differences were observed in the distribution of Bw4 and Bw6 epitopes between infected and not infected children (data not shown).

\begin{tabular}{|c|c|c|c|}
\hline Group Allele A & $\begin{array}{l}\text { Allele frequency in } \\
\text { Exposed infected } n \\
(\%)\end{array}$ & $\begin{array}{c}\text { Allele frequency in } \\
\text { Exposed non infected } \mathbf{n} \\
(\%)\end{array}$ & $P$ value \\
\hline$A^{*} 01$ & $2(2.9)$ & $1(1.8)$ & 0.67 \\
\hline$A^{*} 02$ & $18(26.5)$ & $14(25)$ & 0.84 \\
\hline$A^{*} 03$ & $8(11.8)$ & $4(7.1)$ & 0.38 \\
\hline$A * 11$ & 1 & $4(7.1)$ & 1 \\
\hline$A * 23$ & $6(8.8)$ & $5(8.9)$ & 0.98 \\
\hline$A * 24$ & $1(1.5)$ & $1(1.8)$ & 0.88 \\
\hline$A * 25$ & 1 & $2(3.6)$ & 1 \\
\hline$A * 26$ & $2(2.9)$ & $2(3.6)$ & 0.84 \\
\hline$A^{*} 29$ & $7(10.3)$ & $5(8.9)$ & 0.79 \\
\hline$A * 30$ & $9(13.2)$ & $6(10.7)$ & 0.66 \\
\hline$A * 31$ & $1(1.5)$ & $1(1.8)$ & 0.88 \\
\hline$A * 32$ & $1(1.5)$ & $1(1.8)$ & 0.88 \\
\hline$A * 33$ & $2(2.9)$ & $1(1.8)$ & 0.67 \\
\hline$A * 34$ & 1 & $2(3.6)$ & 1 \\
\hline$A * 36$ & $2(2.9)$ & $1(1.8)$ & I \\
\hline$A^{*} 66$ & 1 & $2(3.6)$ & 1 \\
\hline$A^{*} 68$ & $5(7.4)$ & $3(5.4)$ & 0.65 \\
\hline$A^{*} 74$ & $4(5.9)$ & 1 & 1 \\
\hline$A * 80$ & 1 & $1(1.8)$ & I \\
\hline
\end{tabular}

Table 2: HLA A Allele frequency in exposed non infected and exposed infected infants. 


\begin{tabular}{|c|c|c|c|}
\hline Group Allele B & $\begin{array}{c}\text { Allelle frequency in } \\
\text { Exposed infected } \mathbf{n} \text { (\%) }\end{array}$ & $\begin{array}{c}\text { Allelle frequency in } \\
\text { Exposed non infected } \mathbf{n} \text { (\%) }\end{array}$ & P value \\
\hline $\mathrm{B}^{*} 07$ & $7(10.3)$ & $5(8.9)$ & 0.79 \\
\hline $\mathrm{B}^{*} 08$ & $3(4.4)$ & $1(1.8)$ & 0.41 \\
\hline $\mathrm{B}^{*} 13$ & $/$ & $1(1.8)$ & $/$ \\
\hline $\mathrm{B}^{\star} 14$ & $6(8.8)$ & $3(5.4)$ & 0.45 \\
\hline $\mathrm{B}^{\star} 15$ & $6(8.8)$ & $5(8.9)$ & 0.98 \\
\hline $\mathrm{B}^{*} 18$ & $2(2.9)$ & $5(8.9)$ & 0.14 \\
\hline $\mathrm{B}^{\star} 27$ & $1(1.5)$ & $/$ & $/$ \\
\hline $\mathrm{B}^{*} 35$ & $5(7.4)$ & $6(10.7)$ & 0.5 \\
\hline $\mathrm{B}^{*} 37$ & $/$ & $2(3.6)$ & $/$ \\
\hline $\mathrm{B}^{*} 42$ & $1(1.5)$ & $/$ & $/$ \\
\hline $\mathrm{B}^{*} 44$ & $2(2.9)$ & $7(12.5)$ & $\mathbf{0 . 0 4}$ \\
\hline $\mathrm{B}^{*} 45$ & $1(1.5)$ & $4(7.1)$ & 0.1 \\
\hline $\mathrm{B}^{*} 48$ & $/$ & $1(1.8)$ & $/$ \\
\hline $\mathrm{B}^{*} 49$ & $8(11.8)$ & $3(5.4)$ & 0.2 \\
\hline $\mathrm{B}^{*} 50$ & $/$ & $1(1.8)$ & $/$ \\
\hline $\mathrm{B}^{*} 51$ & $/$ & $1(1.8)$ & $/$ \\
\hline $\mathrm{B}^{*} 52$ & $/$ & $1(1.8)$ & $/$ \\
\hline $\mathrm{B}^{*} 53$ & $7(10.3)$ & $/$ & $/$ \\
\hline $\mathrm{B}^{*} 57$ & $7(10.3)$ & $2(3.6)$ & 0.14 \\
\hline $\mathrm{B}^{*} 58$ & $9(13.2)$ & $8(14.3)$ & 0.86 \\
\hline $\mathrm{B}^{*} 81$ & $3(4.4)$ & $/$ & $/$ \\
\hline
\end{tabular}

Table 3: HLA B Allele frequency in exposed non infected and exposed infected infants.

\begin{tabular}{|c|c|c|c|}
\hline Group Allele A & $\begin{array}{c}\text { Phenotypic frequency } \\
\text { in Exposed infected } \\
\mathbf{N}(\%)\end{array}$ & $\begin{array}{c}\text { Phenotypic frequency in } \\
\text { Exposed non infected N } \\
\text { (\%) }\end{array}$ & P value \\
\hline $\mathbf{A}^{*} \mathbf{0 1}$ & $2(5.9)$ & $1(3.6)$ & 0.67 \\
\hline $\mathbf{A}^{*} \mathbf{0 2}$ & $16(47.1)$ & $11(39.3)$ & 0.54 \\
\hline $\mathbf{A}^{*} \mathbf{0 3}$ & $8(23.5)$ & $4(14.3)$ & 0.35 \\
\hline $\mathbf{A}^{*} \mathbf{1 1}$ & $/$ & $4(14.3)$ & $/$ \\
\hline $\mathbf{A}^{*} \mathbf{2 3}$ & $6(17.6)$ & $5(17.9)$ & 0.98 \\
\hline $\mathbf{A}^{*} \mathbf{2 4}$ & $1(2.9)$ & $1(3.6)$ & 0.88 \\
\hline $\mathbf{A}^{*} \mathbf{2 5}$ & $/$ & $2(7.1)$ & $/$ \\
\hline $\mathbf{A}^{*} \mathbf{2 6}$ & $2(5.9)$ & $2(7.1)$ & 0.84 \\
\hline $\mathbf{A}^{*} \mathbf{2 9}$ & $6(17.6)$ & $4(14.3)$ & 0.71 \\
\hline $\mathbf{A}^{*} \mathbf{3 0}$ & $9(26.5)$ & $5(17.9)$ & 0.41 \\
\hline $\mathbf{A}^{*} \mathbf{3 1}$ & $1(2.9)$ & $1(3.6)$ & 0.88 \\
\hline $\mathbf{A}^{*} \mathbf{3 2}$ & $1(2.9)$ & $1(3.6)$ & 0.88 \\
\hline $\mathbf{A}^{*} \mathbf{3 3}$ & $2(5.9)$ & $1(3.6)$ & 0.67 \\
\hline $\mathbf{A}^{*} \mathbf{3 4}$ & $/$ & $2(7.1)$ & $/$ \\
\hline $\mathbf{A}^{*} \mathbf{3 6}$ & $2(5.9)$ & $1(3.6)$ & 0.67 \\
\hline $\mathbf{A}^{*} \mathbf{6 6}$ & $/$ & $2(7.1)$ & $/$ \\
\hline $\mathbf{A}^{*} \mathbf{6 8}$ & $5(14.7)$ & $3(10.7)$ & 0.63 \\
\hline $\mathbf{A}^{*} \mathbf{7 4}$ & $4(11.8)$ & $/$ & $/$ \\
\hline $\mathbf{A}^{*} \mathbf{8 0}$ & $/$ & $1(3.6)$ & $/$ \\
\hline
\end{tabular}

Table 4: HLA A phenotypic frequency in exposed non infected and exposed infected infants.

\section{Discussion}

The population distribution of HLA alleles and its association to susceptibility or resistance to HIV infection in Cameroon has not been studied but is of particular interest given the HIV/AIDS epidemics afflicting this population. We investigated the genetic diversity of HLA-A, HLA-B alleles in a pediatric population of Cameroon $(\mathrm{N}=62)$, born to HIV infected mothers. HLA-B ${ }^{*} 44$ resulted associated with protection from HIV-infection. It is worth noticing, that in our small

\begin{tabular}{|c|c|c|c|}
\hline Group Allele B & $\begin{array}{l}\text { Phenotypic frequency in } \\
\text { Exposed infected } N(\%)\end{array}$ & $\begin{array}{l}\text { Phenotypic frequency in } \\
\text { Exposed non infected } N(\%)\end{array}$ & P value \\
\hline $\mathrm{B}^{*} 07$ & $7(20.6)$ & $5(17.9)$ & 0.78 \\
\hline $\mathrm{B}^{*} 08$ & $3(8.8)$ & $1(3.6)$ & 0.4 \\
\hline$B^{*} 13$ & 1 & $1(3.6)$ & 1 \\
\hline$B^{*} 14$ & $6(17.6)$ & $3(10.7)$ & 0.44 \\
\hline$B * 15$ & $6(17.6)$ & $4(14.3)$ & 0.71 \\
\hline$B^{*} 18$ & $2(5.9)$ & $5(17.9)$ & 0.13 \\
\hline$B * 27$ & $1(2.9)$ & 1 & I \\
\hline$B * 35$ & $5(14.7)$ & $5(17.9)$ & 0.72 \\
\hline$B * 37$ & I & $2(7.1)$ & I \\
\hline$B^{*} 42$ & $1(2.9)$ & 1 & 1 \\
\hline$B * 44$ & 2(5.9) & $7(25)$ & $0.03^{*}$ \\
\hline$B^{*} 45$ & $1(2.9)$ & $4(14.3)$ & 0.1 \\
\hline$B^{*} 48$ & 1 & $1(3.6)$ & 1 \\
\hline$B * 49$ & $8(23.5)$ & $3(10.7)$ & 0.19 \\
\hline$B^{*} 50$ & 1 & $1(3.6)$ & 1 \\
\hline$B^{*} 51$ & 1 & $1(3.6)$ & 1 \\
\hline$B * 52$ & I & $1(3.6)$ & 1 \\
\hline$B * 53$ & $6(17.6)$ & 1 & 1 \\
\hline$B * 57$ & $6(17.6)$ & $2(7.1)$ & 0.21 \\
\hline$B * 58$ & $9(26.5)$ & $8(28.6)$ & 0.85 \\
\hline$B^{*} 81$ & $3(8.8)$ & 1 & 1 \\
\hline
\end{tabular}

Table 5: Phenotypic frequency in exposed non infected and exposed infected infants.

patient serie we have a pair of twins, exposed but HIV-negative, both exhibiting the HLA B ${ }^{\star} 44$ allele. Their mother did not have this allele, as they may have inherited this allele from their father. In Cameroon, HIV transmission rate is lower in male than in female (5.6\%) [33]. Secondly there are a lot discordant couples where the female is HIV positive and the male HIV negative [33]. HLA B ${ }^{\star} 44$ allele might be involved in protecting the males.

Immunogenetic determinants of host susceptibility and resistance to HIV-1 infection have been an area of intense investigation. In this context, our findings on mother to child transmission of HIV are consistent with the data of the literature. In particular, de Sorrentino et al. [34] reported that the frequencies of HLA $A^{\star} 24, B^{\star} 18$ and $B^{\star} 39$ were increased in HIV-1 positive subjects, while HLA $B^{\star} 44$ and $B^{\star} 55$ were not found in HIV-1 positive subjects, thus suggesting their protective effect. Similarly, Li et al. [35] found that HLA B ${ }^{\star} 44$ allele was significantly increased in HIV-1 seronegative subjects.

Likely due to the small size of our cohort, we did not observe potential protective role of other HLA alleles, such as $\mathrm{B}^{\star} 18, \mathrm{~B}^{\star} 45, \mathrm{~B}^{\star} 49$ and $B^{\star} 50$, that have been described to impact HIV disease. For example, HLA $B^{\star} 18$ has been associated with a significantly lower risk of early HIV-1 transmission from mother to child [36]. HLA- $B^{\star} 45$, $-B^{\star} 49$, and $-B \star 50$ have been found at a moderately increased frequency among individuals responding to HIV-1 infection with a marked circulating and infiltrative CD8 T-cell lymphocytosis, and presenting a slow rate of CD4 T-cell decline, very low frequency of opportunistic infections, and low viral strain heterogeneity [37]. Although HLA-B ${ }^{\star} 57$ (B57) has associated with slow progression to disease following HIV-1 infection, B57 heterozygotes displayed a wide spectrum of outcomes, including rapid progression, viremic slow progression, and elite control [38].

Interestingly, other studies showed that HLA $\mathrm{B}^{\star} 44$ has a protective role in autoimmune lymphoproliferative syndrome in patients with C95 defect [39]. 
Most peptides that bind to a particular MHC class I molecule share amino acid residues that are thought to anchor the peptide to the polymorphic pockets within the binding site. For HLA $\mathrm{B}^{\star} 44$, sequence analysis of endogenous peptides bound revealed two potential dominant residues: Glu at pocket $\mathrm{P} 2$ and Tyr, or occasionally Phe at P9. In vitro assembly assays using synthetic peptides and recombinant HLA B ${ }^{\star} 44$ revealed that an acidic amino acid at P2 was necessary for promoting stable binding. Although Tyr is almost exclusively found at P9, a wide variety of amino acid residues such as Leu, Ala, Arg, Lys, His and Phe could be tolerated at this position [40].

There are two major HLA B ${ }^{\star} 44$ alleles: HLA-B ${ }^{\star} 4402$ and $B^{\star} 4403$ that are both found at a high frequency in all human populations, and yet they only differ by one residue on the $a 2$ helix $\left(B^{\star} 4402\right.$ Asp $156 \rightarrow B^{\star} 4403$ Leu156). CTLs discriminate between HLA-B ${ }^{\star} 4402$ and $B^{\star} 4403$, and these allotypes stimulate strong mutual allogeneic responses reflecting their known barrier to hemopoeitic stem cell transplantation. Although HLA-B ${ }^{\star} 4402$ and $B^{\star} 4403$ share $>95 \%$ of their peptide repertoire, $B^{\star} 4403$ presents more unique peptides than $B^{\star} 4402$, consistent with the stronger $\mathrm{T}$ cell alloreactivity observed toward $\mathrm{B}^{\star} 4403$ compared with $\mathrm{B}^{\star} 4402[41]$.

On the other hand, HLA-B ${ }^{\star} 44$ is carrying the Bw4 epitope. Although we did not find any differences in the Bw4/Bw6 epitope variants in our study population, it is possible that on HLA-B ${ }^{\star} 44$ specific bound peptide(s) might modulate the Bw4 epitope interaction with its ligand for KIR3DL1, an NK's inhibitory receptor, [42,43] suggesting a potential role for the innate immune response in controlling the early event of the HIV infection as well as in the slow progression to AIDS. It is well known that HIV-specific T-cell response, and in particular Cytotoxic T lymphocyte, plays a key role in controlling HIV infection $[44,45]$ As the T-cell response is dictated by HLA molecules, the individual's variation in the HLA class I and II alleles has a profound effect on the outcome of infection and disease progression to AIDS [45,46]. The interaction of NK's inhibitory receptor with HLA regulate innate immune response and might have important implications for a better disease control [47]. In addition, some specific combination of HLA-B ${ }^{\star} 44$ with KIR alleles might be at the basis of the prevention of HIV infection in the mother to child transmission as already described for HIV progression [48].

\section{Conclusion}

HLA-B ${ }^{\star} 44$ is associated with the resistance to HIV infection upon exposure in vertical transmission. The resistance to HIV-1 infection might be in part determined by the binding capability of specific HLA-B restricted epitopes that might either stimulate specific CD8+ T-cell response and/or modulate the interaction with NK's inhibitory receptor.

\section{References}

1. Beck S, Geraghty D, Inoko H, Rowen L (1999) Complete sequence and gene map of a human major histocompatibility complex. The MHC sequencing consortium. Nature 401: 921-923.

2. Bodmer WF (1981) HLA structure and function: a contemporary view. Tissue Antigens 17: 9-20.

3. Trachtenberg E, Korber B, Sollars C, Kepler TB, Hraber PT, et al. (2003) Advantage of rare HLA supertype in HIV disease progression. Nat Med 9: 928935.

4. Stephens HA (2005) HIV-1 diversity versus HLA class I polymorphism. Trends Immunol 26: 41-47.

5. Carrington M, O'Brien SJ (2003) The influence of HLA genotype on AIDS. Annu Rev Med 54: 535-551.

6. Bulterys PL, Dalai SC, Katzenstein DA (2010) Viral sequence analysis from HIV-infected mothers and infants: molecular evolution, diversity, and risk factors for mother-to-child transmission. Clin Perinatol 37: 739-750.
7. MacDonald KS, Embree J, Njenga S, Nagelkerke NJ, Ngatia I, et al. (1998) Mother-child class I HLA concordance increases perinatal human immunodeficiency virus type 1 transmission. J Infect Dis 177: 551-556.

8. Kilpatrick DC, Hague RA, Yap PL, Mok JY (1991) HLA antigen frequencies in children born to HIV-infected mothers. Dis Markers 9: 21-26.

9. Winchester R, Chen Y, Rose S, Selby J, Borkowsky W (1995) Major histocompatibility complex class II DR alleles DRB1*1501 and those encoding HLA-DR13 are preferentially associated with a diminution in maternally transmitted human immunodeficiency virus 1 infection in different ethnic groups: determination by an automated sequence- based typing method. Proc Natl Acad Sci USA 92: 12374-12378.

10. Fabris A, Catamo E, Segat L, Morgutti M, Arraes LC, et al. (2009) Association between HLA-G 3'UTR 14-bp polymorphism and HIV vertical transmission in Brazilian children. AIDS 23: 177-182.

11. Just JJ, Abrams E, Louie LG, Urbano R, Wara D, et al. (1995) Influence of host genotype on progression to acquired immunodeficiency syndrome among children infected with human immunodeficiency virus type 1. J Pediatr 127: 544-549.

12. Cavarelli M, Scarlatti G (2011) HIV-1 co-receptor usage: influence on motherto-child transmission and pediatric infection. J Transl Med 9 Suppl 1: S10.

13. Winchester R, Pitt J, Charurat M, Magder LS, Goring HH, et al. (2004) Motherto-child transmission of HIV-1: strong association with certain maternal HLA-B alleles independent of viral load implicates innate immune mechanisms. J Acquir Immune Defic Syndr 36: 659-670.

14. Aikhionbare FO, Kumaresan K, Shamsa F, Bond VC (2006) HLA-G DNA sequence variants and risk of perinatal HIV-1 transmission. AIDS Res Ther 3 28.

15. Eley B (2006) Addressing the paediatric HIV epidemic: a perspective from the Western Cape Region of South Africa. Trans R Soc Trop Med Hyg 100: 19-23.

16. Lallemant M, Jourdain G, Le Coeur S, Mary JY, Ngo-Giang-Huong N, et al (2004) Single-dose perinatal nevirapine plus standard zidovudine to prevent mother-to-child transmission of HIV-1 in Thailand. N Engl J Med 351: 217-228.

17. Geddes R, Knight S, Reid S, Giddy J, Esterhuizen T, et al. (2008) Prevention of mother-to-child transmission of HIV programme: low vertical transmission in KwaZulu-Natal, South Africa. S Afr Med J 98: 458-462.

18. Slogrove AL, Cotton MF, Esser MM (2010) Severe infections in HIV-exposed uninfected infants: clinical evidence of immunodeficiency. J Trop Pediatr 56: 75-81.

19. Hygino J, Lima PG, Filho RG, Silva AA, Saramago CS, et al. (2008) Altered immunological reactivity in HIV-1-exposed uninfected neonates. Clin Immuno 127: $340-347$.

20. Mussi-Pinhata MM, Freimanis L, Yamamoto AY, Korelitz J, Pinto JA, et al. (2007) Infectious disease morbidity among young HIV-1- exposed but uninfected infants in Latin American and Caribbean countries: the National Institute of Child Health and Human Development International Site Development Initiative Perinatal Study. Pediatrics 119: 694-704.

21. Adhikari M, Kauchali S, Moodley A (2006) Clinical profile and morbidity pattern of infants born to HIV infected mothers in Durban South Africa. Indian Pediatr 43: 804-808.

22. Lin HC, Wang SM, Wu CS, Chang FM, Liu CC (2005) Clinical and immunologic characteristics and therapeutic interventions in children born to human immunodeficiency virus-infected mothers in southern Taiwan. J Microbiol Immunol Infect 38: 89-95.

23. Bunders MJ, Bekker V, Scherpbier HJ, Boer K, Godfried M, et al. (2005) Haematological parameters of HIV-1-uninfected infants born to HIV-1-infected mothers. Acta Paediatr 94: 1571-1577.

24. McNally LM, Jeena PM, Gajee K, Thula SA, Sturm AW, et al. (2007) Effect of age, polymicrobial disease, and maternal HIV status on treatment response and cause of severe pneumonia in South African children: a prospective descriptive study. Lancet 369: 1440-1451.

25. de Moraes-Pinto MI, Almeida AC, Kenj G, Filgueiras TE, Tobias W, et al. (1996) Placental transfer and maternally acquired neonatal IgG immunity in human immunodeficiency virus infection. J Infect Dis 173: 1077-1084.

26. Kuhn L, Meddows-Taylor S, Gray G, Tiemessen C (2002) Human immunodeficiency virus (HIV)-specific cellular immune responses in newborns exposed to HIV in utero. Clin Infect Dis 34: 267-276. 
Citation: Nkenfou CN, Nemes E, Mekue L, Grifoni A, Dambaya B, et al. (2015) Human Leucocyte Antigen Class I Diversity among Human Immunodeficiency Virus Exposed Negative and Positive Children in Cameroon. J AIDS Clin Res 6: 439. doi:10.4172/2155-6113.1000439

Page 5 of 5

27. Embree JE, Njenga S, Datta P, Nagelkerke NJ, Ndinya-Achola JO, et al. (2000) Risk factors for postnatal mother-child transmission of HIV-1. AIDS 14: 25352541.

28. Patel D, Bland R, Coovadia H, Rollins N, Coutsoudis A, et al. (2010) Breastfeeding, HIV status and weights in South African children: a comparison of HIV-exposed and unexposed children. AIDS 24: 437-445.

29. Slogrove AL, Cotton MF, Esser MM (2010) Severe infections in HIV-exposed uninfected infants: clinical evidence of immunodeficiency. J Trop Pediatr 56 75-81.

30. Gesner M, Papaevangelou V, Kim M, Chen SH, Moore T, et al. (1994) Alteration in the proportion of CD4 T lymphocytes in a subgroup of human immunodeficiency virus-exposed-uninfected children. Pediatrics 93: 624-630.

31. 31. Rich KC, Chang BH, Mofenson L, Fowler MG, Cooper E, et al. (1997) Elevated CD8+DR+ lymphocytes in HIV-exposed infants with early positive HIV cultures: a possible early marker of intrauterine transmission, Women and Infants Transmission Study Group. J Acquir Immune Defic Syndr Hum Retrovirol 15: 204-210.

32. Ono E, Nunes dos Santos AM, de Menezes Succi RC, Machado DM, de Angelis DS, et al. (2008) Imbalance of naive and memory T lymphocytes with sustained high cellular activation during the first year of life from uninfected children born to HIV-1-infected mothers on HAART. Braz J Med Biol Res 41: 700-708.

33. National Institute of Statistics (2012) Demographic and Health survey and Multiple Indicators Cluster Survey DHS-MICS Preliminary Report.

34. de Sorrentino AH, Marinic K, Motta P, Sorrentino A, López R, et al. (2000) HLA class I alleles associated with susceptibility or resistance to human immunodeficiency virus type 1 infection among a population in Chaco Province, Argentina. J Infect Dis 182: 1523-1526.

35. Li S, Jiao H, Yu X, Strong AJ, Shao Y, et al. (2007) Human leukocyte antigen class I and class II allele frequencies and HIV-1 infection associations in a Chinese cohort. J Acquir Immune Defic Syndr 44: 121-131.

36. Farquhar $\mathrm{C}$, Rowland-Jones $\mathrm{S}$, Mbori-Ngacha D, Redman M, Lohman B, et al (2004) Human leukocyte antigen (HLA) $B^{*} 18$ and protection against mother-tochild HIV type 1 transmission. AIDS Res Hum Retroviruses 20: 692-697.

37. Itescu S, Rose S, Dwyer E, Winchester R (1995) Grouping HLA-B locus serologie specificities according to shared structural motifs suggests that different peptide-anchoring pockets may have contrasting influences on the course of HIV-1 infection. Human Immunology 42: 81-89.

38. Brennan CA, Ibarrondo FJ, Sugar CA, Hausner MA, Shih R, et al. (2012) Early HLA-B*57-restricted CD8+ T lymphocyte responses predict HIV-1 disease progression. J Virol 86: 10505-10516.

39. Vacek MM, Schäffer AA, Davis J, Fischer RE, Dale JK, et al. (2006) HLA B44 is associated with decreased severity of autoimmune lymphoproliferative syndrome in patients with CD95 defects (ALPS type la). Clin Immunol 118 59-65.

40. DiBrino M, Parker KC, Margulies DH, Shiloach J, Turner RV, et al. (1995) Identification of the peptide binding motif for HLA-B44, one of the most common HLA-B alleles in the Caucasian population. Biochemistry 34: 10130-10138.

41. Macdonald WA, Purcell AW, Mifsud NA, Ely LK, Williams DS, et al. (2003) A naturally selected dimorphism within the HLA-B44 supertype alters class structure, peptide repertoire, and T cell recognition. J Exp Med 198: 679-691.

42. Thananchai H, Gillespie G, Martin MP, Bashirova A, Yawata N, et al. (2007) Cutting Edge: Allele-specific and peptide-dependent interactions between KIR3DL1 and HLA-A and HLA-B. J Immunol 178: 33-37.

43. Vivian JP, Duncan RC, Berry R, O'Connor GM, Reid HH, et al. (2011) Killer cell immunoglobulin-like receptor 3DL1-mediated recognition of human leukocyte antigen B. Nature 479: 401-405.

44. Kaur G, Mehra N (2009) Genetic determinants of HIV-1 infection and progression to AIDS: immune response genes. Tissue Antigens 74: 373-385.

45. McMichael AJ, Rowland-Jones SL (2001) Cellular immune responses to HIV. Nature 410: 980-987.

46. Trachtenberg EA, Erlich HA (2001) A Review of the Role of the Human Leukocyte Antigen (HLA) System as a Host Immunogenetic Factor Influencing HIV Transmission and Progression to AIDS.

47. Montesano C, Bonanno CT, Grifoni A, Di Sano C, Palma P, et al. (2014) Impact of Human Leukocyte Antigen polymorphisms in Human Immunodeficiency Virus progression in a paediatric cohort infected with a mono-phyletic Human Immunodeficiency Virus-1 strain. J AIDS Clin Res 5: 1000282.

48. Jiang Y, Chen O, Cui C, Zhao B, Han X, et al. (2013) KIR3DS1/L1 and HLABw4-80I are associated with HIV disease progression among HIV typical progressors and long-term nonprogressors. BMC Infect Dis 13: 405. 